\title{
Can We Measure Sexual Interest in Pedophiles Using a Sexual Distractor Task?
}

\author{
Kirsten Jordan ${ }^{1 *}$, Peter Fromberger ${ }^{1}$, Jakob von Herder ${ }^{1}$, Henrike Steinkrauss ${ }^{1}$, Rebekka Nemetschek ${ }^{1}$, Joachim Witzel ${ }^{2}$ and Jurgen L Müller ${ }^{1}$ \\ ${ }^{1}$ Department for Forensic Psychiatry and Psychotherapy, Clinic of Psychiatry and Psychotherapy, Georg-August-University of Gottingen, Göttingen, Germany \\ ${ }^{2}$ Central State Forensic Psychiatric Hospital of Saxony-Anhalt, Uchtspringe, Germany
}

"Corresponding author: Kirsten Jordan, Department of Forensic Psychiatry and Psychotherapy, Georg-August University of Gottingen, Rosdorfer Weg, Goettingen 70, 37081, Germany, Tel: 49551 4022104; Fax: 49551 4022110; E-mail: kirsten.jordan@medizin.uni-goettingen.de

Received: June 01, 2016; Accepted: July 20, 2016; Published: July 27, 2016

Copyright: () 2016 Jordan K, et al. This is an open-access article distributed under the terms of the Creative Commons Attribution License, which permits unrestricted use, distribution, and reproduction in any medium, provided the original author and source are credited.

\begin{abstract}
Indirect measures of deviant sexual interest have yielded interesting and promising in the field of pedophilic interest. However, further research is needed. A lot of indirect measures are still at the developmental stage regarding clinical application. They do not reach appropriate psychometric criteria or are not yet sufficiently tested for susceptibility to manipulation or deception. Furthermore, for some paradigms, the exact mechanisms underlying the attentional processes are still under discussion. This study aimed to measure sexual interest under cognitive load. With this challenging active task subject's possibility to manipulate their response to the sexual stimuli should be lower than in easier tasks and in passive designs. Twenty-two pedophiles, seven forensic control subjects and 50 healthy men performed cognitive tasks. Simultaneously, sexually relevant and sexually non-relevant distractors were presented. Meanwhile, their cognitive performance and eye movements were assessed.
\end{abstract}

As expected healthy subjects showed a certain impairment of cognitive performance when sexually relevant distractors were presented to them. They took significantly more time to look at sexual adult distractors than at sexual child distractors. In contrast, both forensic groups performed much poorer than the healthy control group without specificity for certain sexual distractors. While forensic control subjects tended to view adult stimuli longer than those of children, no differences were found for pedophiles. The age preference index for the fixation time differentiated moderately between pedophiles and non-pedophiles.

Our design worked well with healthy subjects. Further studies should examine if an individual adaptation of the task difficulty could help to find the expected cognitive performance impairments of pedophiles and forensic subjects when they are presented with certain distractor categories.

Keywords: Pedophilia; Sexual interest; Attention; Eye movements; Cognitive load

\section{Introduction}

\section{Assessing sexual deviant interest}

Pedophilic disorder, a subtype of paraphilia, is defined as a recurrent sexual interest in prepubescent children, which is characterized by persistent thoughts, fantasies, urges, sexual arousal or behavior [1]. A deviant sexual preference is one of the major predictors for sexual recidivism of sexual offenders [2]. Currently, the Western European standard for the assessment of sexual interest are self-reports. But it is known that self-reports and questionnaires are susceptible to denial or faking [3,4]. It has been suggested to combine self-reports, questionnaires, physiological and indirect measures of sexual deviant interest $[5,6]$. Indirect measures assess either physiological information about the participant or use cognitive approaches of different kinds to gather information, instead of asking the participant directly about his sexuality $[4,7]$.

In recent years a whole range of indirect measures have been developed, which are based on different cognitive approaches [4]. The Implicit Association Test (IAT), for example, is based on the knowledge that (dependent on the individual sexual preference) certain categories are more strongly associated with the concept of sexual arousal than others [8,9]. Subjective sexual arousal can be defined as an emotional experience, which includes the awareness of autonomic arousal, expectation of reward, and motivated desire [10]. Resting upon this definition, the information processing approach of Spiering and Everaerd [11] assumes that sexually relevant features of a stimulus are preattentively selected and automatically induce focal attention to these sexually relevant aspects. Based on this approach, Fromberger et al. [12] used an eye tracking technology to investigate pedophiles in an initial orientation approach. Other measures are based on the theory of limited attention capacity during controlled information processing [13]. The sexual content-induced delay (SCID), which was first proposed by Geer and Bellard [14], occurs when a salient sexual stimulus triggers attentional processes, interfering with or limiting attention to other tasks. The Choice Reaction Time Task (CRT), for example, and the pictorial modified Stroop task rely on this concept $[15,16]$. The viewing time approach, known since 1942, is based on the finding that sexually attractive stimuli are watched longer than sexually unattractive stimuli [17]. It is a common method, especially used by clinicians to assess deviant sexual interest. Some commercial products are available which are based on this concept, e.g., the Abel Assessment for Sexual Interest-2 [18].

Most of these approaches yielded interesting and promising results regarding the measurement of pedophilic interest. Nevertheless, a lot of those measures are still at the developmental stage regarding clinical application. They do not reach appropriate psychometric criteria or are 
not yet sufficiently tested for susceptibility to manipulation or deception. Furthermore, for some paradigms, the exact mechanisms underlying the attentional processes are still under discussion. The pictorial-modified Stroop task, for instance, discriminated between heterosexual and homosexual participants but not between offending (against at least one child) and non-offending participants [16]. Using the CRT, Mokros et al. [15] showed an almost perfect discrimination between child molesters and non-sex offenders. Despite this good discriminant validity, the vulnerability of this task to manipulation or deception remains unclear. Multimodal examinations to assess sexual deviant interest demonstrated promising results with respect to the viewing time approach $[6,19]$. The Explicit and Implicit Sexual Interest Profile (EISIP), for instance, could be useful as an additional diagnostic tool [8]. Still, the mechanisms underlying the viewing time effect remain unclear [20]. Using the initial orienting approach, Fromberger et al. [21] found that pedophiles automatically selected sexual relevant stimuli, but this automatic selection did not trigger focal attention to the sexually relevant stimuli. Thus, despite these promising results, it is clearly necessary to continue the research on the assessment of sexual deviant interest.

\section{Measurement of sexual interest under cognitive load}

From an evolutionary perspective, biological significant stimuli are processed with increased priority to maximize the efficiency of reacting. Thus, early attentional processes allow for a high level of processing even before these stimuli are perceived consciously [22]. For threat stimuli, like spiders or snakes, these survival facilitating mechanisms, i.e., a prioritized and rapid processing, are well known $[23,24]$.

Similar mechanisms have been proposed for sexual stimuli, which are linked to opportunities for reproduction [25]. Consequently, the abovementioned information processing approach of Spiering and Everaerd [11] assumes that sexually relevant features of a stimulus are preattentively selected and automatically induce focal attention to these sexually relevant aspects.

Considering the automatic as well as controlled processing of FYD sexual stimuli, it can be assumed that the processing of sexual features which are presented along with a cognitive task should interfere with the processing of this task. This effect is also known as the aforementioned SCID [14]. Based on the underlying, broader concept of limited attention capacity during controlled information processing [13], sexual features and the cognitive stimulus, compete for the limited attention capacity.

This leads to an interference between the processing of the cognitive task and the processing of the sexual features. Due to the evolutionary importance of sexual features, it has been proposed that performance in the cognitive task should be impaired. Support for this assumption comes from various studies. Within the forensic field, studies applying the CRT [15] or the modified Stroop task [16] showed, though not consistently, a prolonged reaction time when a sexually relevant stimulus was presented along with a cognitive task, compared to a sexually non-relevant stimulus or a neutral stimulus.

\section{Eye movements and measurement of sexual interest}

It has already been shown that eye tracking technology is useful to assess sexual interest. Fromberger et al. [26] used eye tracking technology to measure sexual interest in an initial orientation approach. For healthy hetero- and homosexual subjects, it was shown that relative fixation time was significantly longer, and the number of the first fixations was higher, for sexually preferred stimuli than for sexually non-preferred stimuli [26]. Authors also could distinguish pedophile subjects from non-pedophile subjects based on early attentional processes (fixation latency) with high sensitivity (86.4\%) and high specificity $(90.0 \%)$ [21].

Examining the influence of gender and visibility of sexual cues, Nummenmaa et al. [27] found that heterosexual men and women inspected nude bodies more thoroughly than clothed figures. Men who scored higher on sexual compulsivity dedicated more gaze to the waisthip region when viewing images of their preferred sexual partners than men who scored lower on sexual compulsivity. This effect could not be shown in women [28]. Recently, Bolmont et al. [29] showed that a person's eye gaze shifts as a function of his or her goal (love or lust) when looking at photographs of heterosexual clothed couples or individuals. Decisions which involved love elicited more frequent fixations on the face than on the body. Decisions that involved lust lead to an increase of fixation frequency on the body and a decrease of fixation frequency on the face [29].

\section{Aim of the study and hypotheses}

The objective of the study was to measure sexual interest under cognitive load in pedophiles, forensic control patients and healthy subjects. One advantage of this kind of measurement is that subject's possibility to manipulate their response to sexual stimuli should be lower than in easier tasks and in passive designs. This could be an important point concerning the known tendency in forensic patients to answer in a socially desirable manner or to manipulate responses [30]. Responses of subjects were measured using two methods, which included the recording of reaction time (RT) and error rates and the continuous measurement of eye movements. We hypothesized that the presentation of a sexually relevant distractor throughout a cognitive task leads to a greater impairment of performance in the cognitive task (longer RT, higher error rate) than the presentation of a sexually nonrelevant distractor. Concerning eye movements toward the sexual distractors, it was expected that the latency of the first fixation on a sexually relevant distractor is shorter than the latency of the first fixation on a sexually non-relevant distractor. Furthermore, we hypothesized that the fixation time for sexually relevant distractors is longer than to sexually non-relevant relevant distractors. It was expected to find these effects within all groups. Group differences were expected with respect to the distractor category (i.e., an adult or a child distractor). Data were further analyzed to proof if behavioral and eye movement variables would coincide with subjects' group status on a better- than- chance level, especially concerning pedophilic and nonpedophilic subjects.

\section{Methods}

\section{Participants}

Altogether, data of 22 male pedophilic subjects, seven male forensic inpatients without any history of sexual assault against children and 50 male healthy subjects were analyzed. The current study was part of a larger project $[12,21]$. Data, just of the non-forensic control group are presented [31]. Healthy subjects were recruited via a notice posted on bulletin boards in Göttingen and on inquiry at a police-officer school. Pedophilic subjects and forensic control subjects were recruited at high-security, forensic-psychiatric hospitals. Inclusion criteria for the pedophilic group were a cross-validated diagnosis of pedophilia 
Citation: Jordan K, Fromberger P, von Herder J, Steinkrauss H, Nemetschek R, Witzel J, Müller JL (2016) Can We Measure Sexual Interest in Pedophiles Using a Sexual Distractor Task?. J Foren Psy 1: 109. doi:10.4172/2475-319X.1000109

Page 3 of 14

(ICD-10 F65.4) by two experienced clinicians and mandatory hospitalization under treatment order for a child-sexual-abuse offense (validated through forensic records). Inclusion criteria for the forensic control group were the absence of a diagnosis of, no child-sexual-abuse offense, and mandatory hospitalization under treatment order for an adult-sexual-abuse offense (validated through forensic records). Inclusion criteria for the healthy, non-forensic control group were the absence of any psychiatric illnesses, deviant sexual fantasies or behavior (validated by an extensive psychiatric and sexual anamnesis conducted in a systematic oral interview about the case history of the subject by one experienced clinician). Exclusion criteria (especially for the inpatient groups) were an acute psychotic episode or substance abuse during the previous month, no agreement between the two clinicians with respect to the diagnosis of pedophilia, or incapability or refusal to sign informed consent. Due to these specifications and other conditions (e.g., no informed consent, technical problems) 36 (three pedophiles and 33 non-pedophiles) out of 65 screened forensic inpatients had to be excluded for the current analysis. Two healthy subjects (out of 52) had to be excluded from the analysis due to technical problems.

\begin{tabular}{|c|c|c|c|c|}
\hline & Pedophiles & $\begin{array}{l}\text { Forensic } \\
\text { controls }\end{array}$ & $\begin{array}{l}\text { Non-forensic } \\
\text { controls }\end{array}$ & Test-statistic $^{1}$ \\
\hline Number of subjects & $\mathrm{N}=22$ & $N=7$ & $\mathrm{~N}=50$ & \\
\hline \multicolumn{5}{|l|}{ Sexual orientation } \\
\hline Heterosexual & $9(40.9 \%)$ & $7(100 \%)$ & $34(68 \%)$ & $x^{2}(2)=9.28, p=0.010$ \\
\hline homosexual & $7(31.8 \%)$ & $0(0 \%)$ & $16(32 \%)$ & $X^{2}(2)=3.16, p=0.210$ \\
\hline bisexual & $6(27.3 \%)$ & $0(0 \%)$ & $0(0 \%)$ & $X^{2}(2)=16.82, p<0.001$ \\
\hline \multicolumn{5}{|l|}{ ICD-10 diagnosis ${ }^{2}$} \\
\hline Pedophilia (F65.4) & $22(100 \%)$ & $0(0 \%)$ & $0(0 \%)$ & $X^{2}(2)=79.00, p<0.001$ \\
\hline Substance abuse / dependence (F10-F19) & $9(40.9 \%)$ & $2(28.6 \%)$ & $0(0 \%)$ & $X^{2}(2)=22.71, p<0.001$ \\
\hline Schizophrenia (F20-F29) & $3(13.6 \%)$ & $2(28.6 \%)$ & $0(0 \%)$ & $X^{2}(2)=11.20, p=0.004$ \\
\hline Neurotic disorders (F40-F49) & $2(9.1 \%)$ & $0(0 \%)$ & $0(0 \%)$ & $X^{2}(2)=5.32, p=0.07$ \\
\hline Personality disorders (F60-F69) & $9(40.9 \%)$ & $4(57.1 \%)$ & $0(0 \%)$ & $X^{2}(2)=20.06, p<0.001$ \\
\hline Mental disorders (F70-F79) & $3(13.6 \%)$ & $0(0 \%)$ & $0(0 \%)$ & $X^{2}(2)=8.10, p=0.018$ \\
\hline Developmental disorders (F80-F89) & $1(4.5 \%)$ & $0(0 \%)$ & $0(0 \%)$ & $X^{2}(2)=2.62, p=0.27$ \\
\hline Behavioral disorders with onset in childhood (F90-F99) & $1(4.5 \%)$ & $0(0 \%)$ & $0(0 \%)$ & $X^{2}(2)=2.62, p=0.27$ \\
\hline \multicolumn{5}{|l|}{ Demographic data ${ }^{3}$} \\
\hline Age, years (SD) & $42.09(10.92)$ & $34.86(14.28)$ & $25.38(7.39)$ & $F(2,76)=26.05, p<0.001, \eta^{2}=0.41$ \\
\hline Intelligence, overall mean IQ (SD) & $76.52(16.65)$ & $78.14(7.14)$ & $117.88(11.03)$ & $F(2,75)=95.60, p<0.001, \eta^{2}=0.72$ \\
\hline Hospitalization, month (SD) & $121.82(68.02)$ & $116.00(112.62)$ & $0(0)$ & $F(2,76)=58.41, p<0.001, \eta^{2}=0.61$ \\
\hline \multicolumn{5}{|l|}{ General Mental Rotation performance } \\
\hline \multirow[b]{4}{*}{ MRT-Score } & $5.05(3.91)$ & $5.00(2.28)$ & $12.24(3.94)$ & Group: $F(2,71)=1.48, p=0.235, \eta^{2}=0.04$ \\
\hline & - & - & - & Age: $F(1,71)=2.17, p=0.145, n^{2}=0.03$ \\
\hline & - & - & - & IQ: $F(1,71)=7.24, p=0.009, \eta^{2}=0.09$ \\
\hline & - & - & - & Hosp: $F(1,71)=0.48, p=0.489, \eta^{2}=0.01$ \\
\hline
\end{tabular}

Table 1: Detailed characteristics of the subject groups. Shown are sexual orientations, ICD-10 diagnosis, demographic data and scores in the Mental Rotations Test (MRT).

From the Table 1: ${ }^{1}$ Test statistic for sexual orientation and ICD10diagnosis: Chi-square test; Test statistic for demographic data: univariate general linear model (GLM) with the factor Group. Test statistic for the mental rotation test (MRT, Peters, et al. [40]): univariate general linear model with the factor Group and covariates Age, Intelligence and Hospitalization.

${ }^{2}$ Only those ICD-diagnosis are presented, which were appropriate for at least one subject Participants with an F10-F19 ICD-10 diagnosis 
had no active substance abuse at least in the last month. Participants with an F20-29 ICD-10 diagnosis had no acute psychotic episode at least during the last month Personality disorders (without F65.4) were assessed with SKID-II.

${ }^{3}$ Age: post-hoc pair wise Comparisons (Bonferroni) yielded significant differences between the non-forensic control group and both, the pedophiles $(\mathrm{p}<0.001)$ the non-forensic control group $(\mathrm{p}=0.04)$ Intelligence: Test statistics: post-hoc pair wise Comparisons (Bonferroni) yielded significant differences between the non-forensic control group and both, the pedophiles $(\mathrm{p}<0.001)$ and the forensic control group $(\mathrm{p}<0.001)$ Hospitalization reflects the overall time duration of the subjects in forensic hospitals Test statistics: post-hoc pair wise Comparisons (Bonferroni) yielded significant differences between the non-forensic control group and both, the pedophiles $(\mathrm{p}<0.001)$ and the forensic control group $(\mathrm{p}<0.001)$.

Table 1 summarizes the characteristics of the three groups of participants with regard to sexual orientation and ICD-10 diagnosis. For the pedophilic group and the forensic control group, sexual orientation was assessed based on the victims' gender. Sexual orientation of non-forensic controls was assessed with the Kinsey-scale [32], accepting only ratings from 0 to 1 (exclusively and predominantly heterosexual) or 5 to 6 (predominantly or exclusively homosexual). As shown in Table 1, the three groups were not homogeneous with regard to their sexual orientation.

The pedophilic participants demonstrated a median score of 5.00 (range: 2-5) on the Screening Scale for Pedophilic Interests, which identified the group as a high-risk sample with respect to recidivism $[33,34]$. The pedophilic group had been convicted for sexually abusing an average of 6.05 children ( $\mathrm{SE}=1.03$, range: $1-22$ ). Child victims were, on average, 9.03 years of age ( $\mathrm{SE}=0.47$ years, range: $3.50-12.50$ years). Groups differed with respect to age, intelligence and hospitalization (Table 1). Mostly, the healthy control group differed from both forensic groups. With respect to the potential significant influence of the three factors on task performance, these factors were included as covariates in all statistical analyses comparing groups.

All participants had normal or corrected-to-normal visual acuity. All of them provided written informed consent before participating in the experiment. The study was approved by the Ethics Committee of the Medical Faculty of Georg-August University of Göttingen.

\section{Assessment of general mental rotation performance}

The classical mental rotation of three-dimensional figures was first described by Shepard and Metzler [35]. Meantime, mental rotation of three-dimensional figures has been applied in a broad range of psychological and neuroscience research [36,37]. Typically, pairs of two- or three-dimensional cube figures are presented, either identical and rotated or mirrored and rotated. The angle of rotation between the figures ranges from $20^{\circ}$ to $180^{\circ}$. Subjects have to decide if the two figures are identical or not. For identical figures, the RT increases linearly with angular disparity. This has led to the assumption that the underlying cognitive process can be understood as a mental representation of the actual physical process of aligning both figures in order to assess the identity of the figures [35]. Increased angular disparities are also associated with increased error rates, which probably reflects task difficulty [38].

The general mental rotation performance was assessed using a German language version of the redrawn Vandenberg and Kuse [39] Mental Rotations Test (MRT) by Peters et al. [40] (Supplementary material S1). Furthermore, the basic mental rotation performance was assessed using a computerized and modified version of the classical mental rotation task, first described by Shepard and Metzler [35]. This task is the same which was used in the sexual distractor task, but without sexual distractors (Figure 1). Pairs of three-dimensional cube figures were presented, identical and rotated $(n=32)$, or mirrored and rotated $(n=32)$. Stimuli were taken from a larger stimulus set which was developed by Paschke et al. [41]. In our study, we chose a fixed angular disparity of $80^{\circ}$ that had been associated with moderate error rates of about $10 \%$ in the study by Paschke et al. [41]. Subjects responded via the press of one of two buttons to judge the stimulus parity. Each trial ended either after button press or after $10 \mathrm{sec}$. To introduce subjects to the stimuli and the task, a training experiment was conducted. During training, a feedback was given regarding the speed and accuracy of the answer after each test trial. To avoid practice effects, the sexual distractor task was given in a time interval of at least a week after the assessment of basic mental rotation performance.

\section{Sexual distractor task}

Mental rotation stimuli: Pairs of three-dimensional cube figures were the same as used for the basic mental rotation task (as above). In order to increase the number of stimuli, each pair of mental rotation figures was presented twice, once on the right side of the screen and once on the left side, resulting in a total of 128 stimuli.

Sexual distractor stimuli: Sexual stimuli were taken from the NotReal-People (NRP) picture set [42]. The NRP picture set consists of a total of 160 colored images of partially dressed and nude people of both genders at five different stages of pubertal development, according to Tanner's categorization $[43,44]$. The images are nonpornographic in terms of explicit sexual poses or sexual activity. In this study, 64 nude male and female images were used. Male and female stimuli of Tanner stages 1 and 2 were combined to make up the distractor categories "boy" and "girl". "Woman" and "man" distractor categories were comprised of Tanner stages 4 and 5. Mirrored images were generated to enlarge the number of available stimuli.

\section{Combination of mental rotation stimuli and sexual distractors}

Stimulus displays consisted of a horizontal presentation of the mental rotation stimulus and a distractor stimulus out of one of the four categories woman, man, girl or boy. Examples of the stimuli displays are shown in Figure 1. The rotation stimuli and distractors were positioned in a way that their center points lay $12^{\circ}$ of visual angle apart, assuming a viewing distance of $70 \mathrm{~cm}$. The sides of display as well as the combinations of distractor categories and rotation stimuli were balanced across trials. Using each distractor stimulus twice, once as a mirrored copy and once in its original orientation, we achieved a total of 64 Stimuli, 16 per distractor category. Every distractor was seen twice in combination with different types of rotation tasks resulting in 128 trials altogether.

To control low-level visual features such as colour, luminance, contrast and visual complexity [45], all images were converted into grey scale and processed with a self-developed Matlab script (Matlab Version 7.6.0, MathWorks Inc.) to even out significant differences in luminance and contrast. The backgrounds of images were replaced by a monochrome grey. As the mean file size of files in JPEG format is correlated positively with their visual complexity [46], a comparison between mean byte number between distractor categories helped to 
Citation: Jordan K, Fromberger P, von Herder J, Steinkrauss H, Nemetschek R, Witzel J, Müller JL (2016) Can We Measure Sexual Interest in Pedophiles Using a Sexual Distractor Task?. J Foren Psy 1: 109. doi:10.4172/2475-319X.1000109

Page 5 of 14

further rule out confounding bottom-up attentional bias [26]. Stimuli were presented on a 19 -inch TFT flat screen $(1280 \times 1024$ pixels, 75 $\mathrm{Hz})$.

\section{Eye tracking device}

Eye movements were measured using an SMI iView X RED eye tracker (SensoMotoric Instruments BmGH, Berlin, Germany) in combination with an iView X workstation (spatial solution $<0.1^{\circ}$ of visual angle, temporal solution $60 \mathrm{~Hz}$, gaze position accuracy of $<0.4^{\circ}$ of visual angle). Eye movements were recorded with a video-based infrared eye camera using corneal reflection and dark pupil method. The SMI RED system is a contact free, remote controlled eye tracking device with automatic eye and head tracking, assuring that slight head movements are automatically compensated (within a range of approx.
$40 \mathrm{~cm}$ ). Although it was not necessary to immobilize the head of the participants, we needed to ensure that they did not move out of the compensable range. We therefore asked the subjects to rest their chins on their non-dominant hands.

\section{Procedure}

Participants were seated in a quiet room facing the monitor at eye level at a viewing distance of $70 \mathrm{~cm}$ from the monitor. To introduce subjects to the sexual distractor task, a training experiment was conducted. During training, only clothed sexual distractor stimuli and pairs of mental rotation figures were presented, which were not included in the main task. A feedback was given regarding the speed and accuracy of the answer after each test trial.

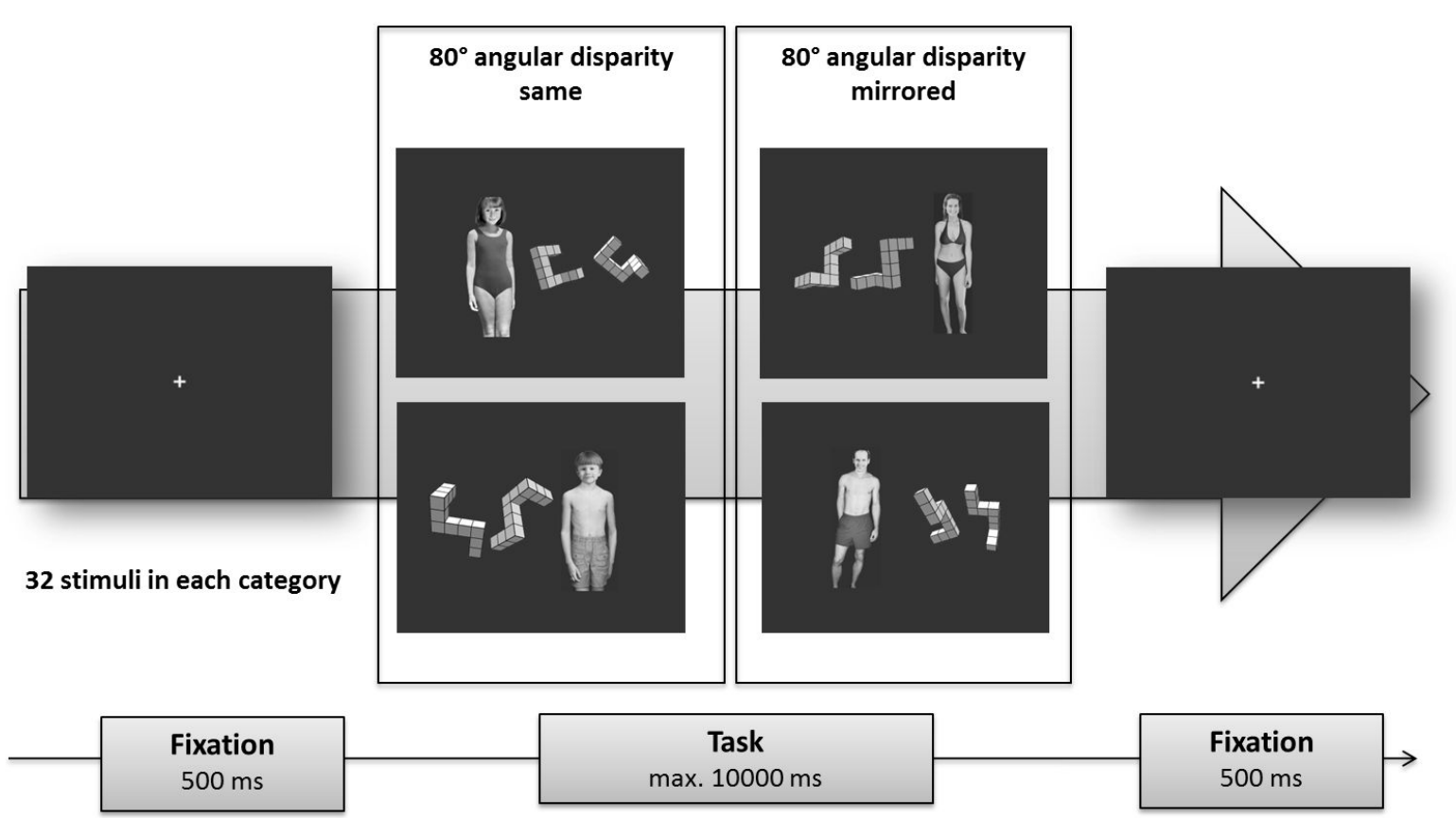

Figure 1: Experimental design. Given are examples for each condition. For each mental rotation task one sexual distractor simultaneously was presented, a girl, boy, woman or man (note that these stimuli were not included in the main task). Sexual distractor stimuli were taken from the NRP-set [42]. Mental rotation stimuli were selected from the set developed by Paschke et al. [41]. More details in methods section.

The experiment itself was divided into four blocks of 32 trials which were each preceded by a 9-point calibration of the eye tracker and after which participants could rest for as long as they felt the need to. Before each trial, a fixation cross appeared in the center of the screen to ensure a central gaze position at the beginning of a trial. Stimulus presentation was triggered if participants continuously fixated the cross for $500 \mathrm{~ms}$ as indicated by a red circle appearing around it. Subjects responded via the press of one of two buttons to judge the stimulus parity. Each trial ended either after button press or after 10 sec. During the whole experiment RTs, button presses and eye movements were recorded. Subsequent to the experimental phase, the participants rated all sexual distractor stimuli with respect to valence and sexual arousal on a nine-point Likert scale (1=unpleasant/not arousing, 9=pleasant/arousing). The time between stimulus onset and completion of the second rating was measured without the participant's knowledge in order to additionally assess viewing time [43].

\section{Data Analysis}

\section{Behavioral data}

For the MRT a score for each subject was calculated. Credit for an item was given only if both correct alternatives had been found so that each subject could reach a maximum score of 24 (Supplementary material S1). Mean RT for correct answers and error rate for each subject were calculated in order to analyze basic mental rotation performance. In the sexual distractor task, mean RT for correct answers and error rate were calculated with respect to sexual distractor categories which were simultaneously presented with the mental rotation stimulus. RT values below $150 \mathrm{~ms}$ were excluded from analysis. 


\section{Eye movements}

Raw eye movements were analyzed using BeGaze 3 (Sensomotoric Instruments $\mathrm{GmbH}$, Berlin, Germany) to identify fixations [26]. Fixations were defined as periods of relative stability of gaze position within a field of $1^{\circ}$ of visual angle for at least $100 \mathrm{~ms}$ [47]. Different areas of interest (AOIs) were marked in order to analyze visual attention to the different stimuli. Each pair of mental rotation figures equated to one AOI, and each image of a woman, girl, boy or man served as one AOI. Two eye movement parameters were analyzed. The fixation latency was defined as the duration from stimulus onset to the first fixation within a specific AOI. Fixation latency is thought to represent attentional bias owed to early, automatic shifts in attention, especially if it represents the first fixation in a trial $[21,48]$. In contrast, fixation time is known to reflect controlled, sustained attention, e.g., late, mostly top down endogenous control of attention [48]. Fixation time was measured as relative fixation time, i.e., the sum of fixation duration of all fixations located within the relevant AOI, divided by the whole presentation time of each task. The latter was restricted either by the response time of the participant or by the maximum presentation time of the task, $10 \mathrm{sec}$.

\section{Statistical Analyses}

All statistics were performed with IBM SPSS Statistics 22.0 (IBM Corp. and other(s) 1989, 2013, New York, USA). To control for the unequal distribution of general sexual orientations within the three groups, only the sexually relevant images with respect to gender were analyzed [15,21]. Hence, for heterosexual participants, only images of females (girls and women) and, for homosexual participants only images for males (boys and men) were included. For bisexual participants, images of both males and females were included in the analysis. This strategy resulted in two sexual age categories: Child and adult. To emphasize that the sexual stimuli served in the sexual distractor task as sexual distractors they were referred to as "sexual distractors".

Differences within groups regarding valence and arousal ratings were analyzed using Wilcoxon Signed-Rank tests. Group differences for the valence and arousal ratings were analyzed applying KruskallWallis Test. Post-hoc tests were performed using Mann-Whitney Tests. A $3 \times 2$ (Group [non-forensic control, forensic control, pedophiles] $\times$ Distractor category [child, adult]) mixed design GLM with the covariates age, intelligence and hospitalization was performed to ask for between group differences with respect to viewing time. Differences within the groups regarding viewing time, mental rotation performance and eye movements in the sexual distractor task were analyzed applying univariate repeated measure GLMs with distractor category (adult distractor, child distractor) as within factor. To ask for between group differences $3 \times 2$ (Group [non-forensic control, forensic control, pedophile] $\times$ Distractor category [child, adult]) mixed design GLMs with the covariates age, intelligence and hospitalization were performed. All post-hoc tests were performed by Bonferroni corrected two-tailed comparisons. Additionally, all analyses were performed without covariates. Results of these raw analyses are presented in the supplementary material (Tables S4 and S5).

\section{Age preference index}

An age preference index (API) was calculated for each subject in order to test how well performance and eye movement parameters differentiate between pedophilic and non-pedophilic subjects regarding their sexual interest to child or adult sexual distractors $[15,21]$. The API was defined as difference between performance resp. eye movement parameters towards adult and child distractor stimuli. A low API for RT or error rate represented a shorter RT or lower error rate, respectively, in the mental rotation task, if an adult distractor was simultaneously presented compared to a child distractor. A low API for fixation latency meant shorter fixation latencies for adult sexual distractors compared to child sexual distractor. A higher API for relative fixation time stood for a longer fixation time for adult sexual distractors compared to child distractors. Univariate GLM's were computed to explore whether the API for performance and eye movement parameters differentiated between pedophiles and nonpedophiles. Only if significant group differences were found, ROCanalyses were added. The cut-off criterion was determined following the approach by Youden [49]. Following this approach, the optimal cut-off point is the threshold that maximizes the distance to the identity (diagonal) line. The optimal criterion is defined as $y=\max$ (sensitivities+specificities).

\section{Results}

\section{General mental rotation performance}

Table 1 presents the mean MRT-scores and statistics with respect to the subject group. The non-forensic control group showed higher MRT-scores than both forensic groups, whereas similar scores were found for both forensic groups. The analysis of covariance with age, intelligence and hospitalization as covariates revealed that the group differences regarding the MRT-score could mainly be explained by differences regarding intelligence (Table 1). For the basic mental rotation performance, lowest RT and lowest error rate were found for the non-forensic control group, compared to both forensic groups (Supplementary material, Table S2). The analysis of covariance for RT with age, intelligence and hospitalization revealed that group differences could partially be explained by age differences. For error rates the analysis of covariance showed that group effects were mainly due to significant differences regarding intelligence. Results of raw analysis without covariates are presented in Table S4.

\section{Stimulus rating}

Table 2 presents the medians of the sexual arousal and valence ratings, and means and standard errors of the viewing time as a function of subject group.

\section{Sexual arousal rating}

Pedophiles and non-forensic controls rated adults as significantly more arousing than child stimuli (pedophiles: $U=-2.20, p=0.028$, nonforensic controls: $U=-5.98, p<0.001)$. The same pattern was seen for the forensic controls, but only by trend $(\mathrm{U}=-1.83, \mathrm{p}=0.068)$. For the whole group, sexual arousal ratings differed significantly within the adult and within the child distractor category (adult: $\chi^{2}(2)=14.36, p=0.001$, child: $\left.\chi^{2}(2)=20.81, p<0.001\right)$. The non-forensic control group rated adults significantly higher than forensic controls $(\mathrm{Z}=-3.66, \mathrm{p}<0.001)$. Pedophiles demonstrated significantly higher sexual arousal ratings for child stimuli than both control groups (pedophiles vs. forensic control: $\mathrm{Z}=-2.78, \mathrm{p}=0.005$, pedophiles vs. non-forensic control: $\mathrm{Z}=-4.10$, $\mathrm{p}<0.001)$. No further group differences were found. 


\section{Valence rating}

All three groups rated stimuli of adults significantly higher on valence scale than child stimuli (pedophiles: $U=-3.07, p=0.002$, nonforensic control: $U=-5.79, p<0.001$, forensic control: $U=-2.04, p$ $=0.041)$. The analysis for the whole group showed that valence ratings differed significantly within both stimulus categories (adult: $\chi^{2}(2)=11.50, p=0.003$, child: $\chi^{2}(2)=6.99, p=0.030$ ). Post-hoc tests demonstrated higher valence ratings for adult stimuli in the nonforensic control group compared to the forensic control group $(\mathrm{Z}=-3.30, \mathrm{p}=0.001)$. Pedophiles and non-forensic controls rated child stimuli higher on the valence scale than forensic controls (pedophiles vs. forensic control: $Z=-2.16, p=0.031$, non-forensic control vs. forensic control: $Z=-2.59, p=0.009$ ). All other post-hoc tests revealed no significant differences.

\section{Viewing time}

Both control groups viewed adults longer than child stimuli. This difference was significant for the non-forensic control group $(t$ $(49)=7.00 \mathrm{p}<0.001)$, but did not achieve statistical significance in the forensic control group $(\mathrm{t}(6)=1.62, \mathrm{p}=0.157)$. For pedophiles, viewing time for adult and viewing time for child stimuli did not differ significantly ( $\mathrm{t}(20)=1.00, \mathrm{p}=0.329)$. Comparing groups, the mixed design GLM with covariates revealed a main effect for the distractor category by trend $\left(\mathrm{F}(1,70)=3.93, \mathrm{p}=0.051, \mathrm{\eta}^{2}=0.05\right)$ and a significant Group $\times$ Distractor category interaction $(\mathrm{F}(2,70)=9.32, \mathrm{p}<0.001$, $\left.\eta^{2}=0.21\right)$. No main effect for the group was found $(F(2,70)=2.05$, $\left.\mathrm{p}=0.136, \eta^{2}=0.06\right)$. The age of the subjects had a significant influence on the viewing time $\left(\mathrm{F}(1,70)=10.42, \mathrm{p}=0.002, \mathrm{\eta}^{2}=0.13\right)$. Older subjects showed longer viewing time. The post-hoc univariate GLM for the adult stimuli failed to show a significant main effect for the group ( $\mathrm{F}$ $\left.(2,70)=0.68, p=0.507, \eta^{2}=0.05\right)$. Again, the age of the subject had an significant influence on the viewing time $(\mathrm{F}(1,70)=8.34, \mathrm{p}=0.005$, $\left.\eta^{2}=0.11\right)$ with longer viewing time in older subjects. In contrast, the univariate GLM for the child stimuli yielded a significant group effect ( $\left.F(2,70)=6.11, p=.004, \eta^{2}=0.15\right)$. Pairwise Bonferroni corrected comparisons showed that pedophiles viewed child stimuli significantly longer then subjects of the non-forensic control group $(\mathrm{p}=0.005)$. The age of the subjects and the months of hospitalization had a significant influence on viewing time (age: $F(1,70)=9.51, p=0.003, \eta^{2}=0.12$, hospitalization: $\left.\mathrm{F}(1,70)=6.78, \mathrm{p}=0.011, \mathrm{\eta}^{2}=0.09\right)$. Viewing time was longer in older subjects and subjects with longer duration of hospitalization. No further significant differences were seen.

\begin{tabular}{|c|c|c|c|c|}
\hline & Stimulus age & Pedophiles & Forensic controls & Non-forensic controls \\
\hline Rating & category & $N=21$ & $N=7$ & $N=49$ \\
\hline \multicolumn{5}{|c|}{ Sexual arousal median (range) } \\
\hline & Adult & $4.25(1.00-9.00)$ & $1.50(1.00-5.00)$ & $6.00(1.00-9.00)$ \\
\hline & Child & $2.00(1.00-8.00)$ & $1.00(1.00-1.00)$ & $1.00(1.00-7.00)$ \\
\hline \multicolumn{5}{|c|}{ Valence median (range) } \\
\hline & Adult & $5.75(1.00-9.00)$ & $4.00(1.00-6.00)$ & $6.50(3.00-9.00)$ \\
\hline & Child & $2.00(1.00-7.50)$ & $1.00(1.00-3.00)$ & $2.50(1.00-7.50)$ \\
\hline \multicolumn{5}{|c|}{ Viewing Time [ms] } \\
\hline & Adult & $8400.55(2602.75)$ & 6366.08 (1921.63) & 7361.05 (2634.05) \\
\hline Mean (SD) & Child & 7994.76 (2910.94) & $5060.73(1664.60)$ & $5404.58(2380.41)$ \\
\hline
\end{tabular}

Table 2: Sexual arousal, valence ratings and viewing time by stimulus category and subject group. Ratings based on a nine-point Likert scale (1=unpleasant/not arousing; 9=pleasant/arousing).

\section{Mental rotation performance in the sexual distractor task}

Figure 2 presents the means and standard errors for mental rotation performance in the sexual distractor task with respect to the two different sexual distractors (i.e., child, adult).

\section{Mental rotation performance - results within groups}

In the non-forensic control group, significant main effects were found for the distractor category $\left(\mathrm{RT}: \mathrm{F}(1,49)=6.62, \mathrm{p}=0.013, \mathrm{\eta}^{2}=0.12\right.$, error rate: $\left.F(1,49)=5.4, p=0.024, \eta^{2}=0.10\right)$. Longer $R T s$ and higher error rates were seen in the mental rotation task if an adult sexual distractor was simultaneously presented compared to a child sexual distractor ( $R T: p=0.012$, error rate: $p=0.024$ ). Neither pedophiles nor the forensic controls showed a main effect for the distractor category for RT (pedophiles: $\mathrm{F}(1,21)=0.5, \mathrm{p}=0.489, \mathrm{\eta}^{2}=0.02$, forensic control: $\mathrm{F}$ $\left.(1,6)=0.03, p=0.864, \eta^{2}=0.005\right)$. The same pattern was seen for the error rate: Pedophiles: $\mathrm{F}(1,21)=1.6, \mathrm{p}=0.218, \eta^{2}=0.07$, forensic control: F $(1,6)=1.15, \quad p=0.325, \eta^{2}=0.16$. Thus, in forensic groups, no performance effect was seen with respect to the distractor category.

\section{Mental rotation performance - results between groups}

Figure 2a demonstrates clearly shorter RTs in the non-forensic control group than in both forensic groups (Table S5 for analyses without covariates). Including covariates, mixed design GLM for the RT yielded a significant main effect for the group $(F(2,72)=4.9$, $\mathrm{p}=0.010, \mathrm{n}^{2}=0.12$ ), but not for the distractor category (Table 3 ). The covariates age of the subjects $\left(\mathrm{F}(1,72)=9.2, \mathrm{p}=0.003, \eta^{2}=0.11\right)$ and 
Citation: Jordan K, Fromberger P, von Herder J, Steinkrauss H, Nemetschek R, Witzel J, Müller JL (2016) Can We Measure Sexual Interest in Pedophiles Using a Sexual Distractor Task?. J Foren Psy 1: 109. doi:10.4172/2475-319X.1000109

Page 8 of 14

hospitalization $\left(\mathrm{F}(1,72)=5.05, \mathrm{p}=0.028, \mathrm{\eta}^{2}=0.07\right)$ had a significant influence, but not the intelligence. Pairwise comparisons demonstrated significant lower RTs for the non-forensic control group compared to the forensic control group ( $\mathrm{p}=0.008$; Figure 2a). No interactions were found.

Concerning errors in the mental rotation task, the non-forensic control group exhibited lowest error rate (about 8\%) compared to both forensic groups with error rates about $25 \%$ to $30 \%$ (Figure $2 \mathrm{~b}$ and Table
S5 for analysis without covariates). These large group differences could mainly be explained by differences regarding the covariates intelligence and age. The mixed design GLM revealed no main effect for the group. A significant influence of intelligence $(F(1,72)=20.62, p<0.001$, $\left.\eta^{2}=0.22\right)$ and age $\left(\mathrm{F}(1,71)=4.59, \mathrm{p}=0.036, \eta^{2}=0.06\right)$ was demonstrated. No further significant main effects or interactions were found (Table $3)$.

\section{(A)}

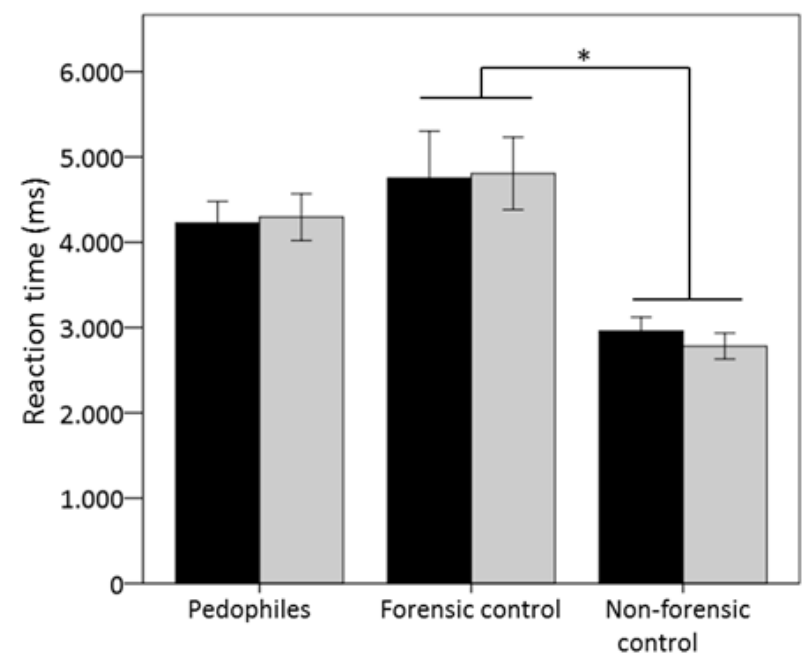

Mental rotation stimuli with adult sexual distractors

$\square$ Mental rotation stimuli with child sexual distractors

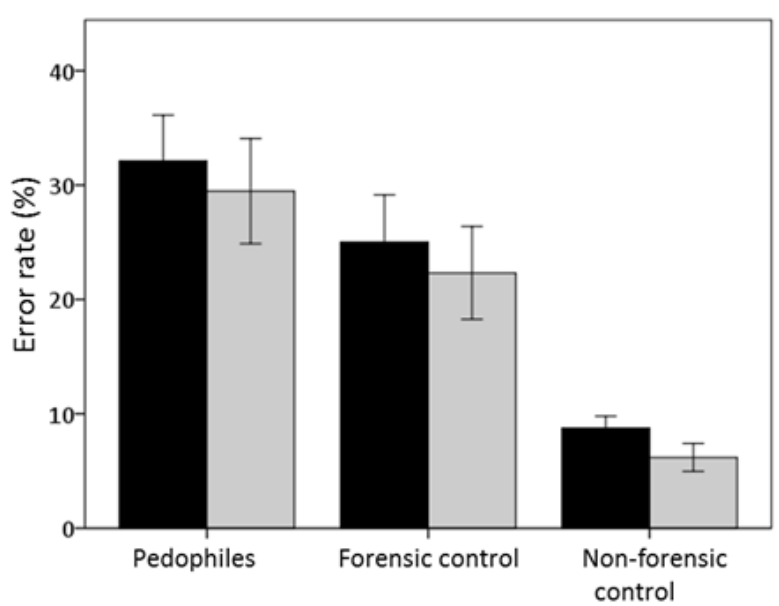

Figure 2: Mental rotation performance in the sexual distractor task with respect to subject group. Means and standard errors are shown of the RT for correct answers (A) and error rate (B). Black bars: Mental rotation performance if the sexual distractor was an adult. Grey bars: Mental rotation performance if the sexual distractor was a child. ${ }^{*} \mathrm{p}<0.05$ significant differences between forensic control group and the non-forensic control group independently of distractor category.

\begin{tabular}{|c|c|c|c|c|}
\hline Dependent & Test-statistic ${ }^{1}$ & Test-statistic ${ }^{2}$ & Test-statistic $^{2}$ & Test-statistic ${ }^{2}$ \\
\hline Variable & Overall group differences & $\begin{array}{l}\text { Pedophiles vs. } \\
\text { forensic controls }\end{array}$ & $\begin{array}{l}\text { Pedophiles vs. non- } \\
\text { forensic controls }\end{array}$ & $\begin{array}{l}\text { Forensic controls } \\
\text { vs. non-forensic } \\
\text { controls }\end{array}$ \\
\hline \multirow[t]{6}{*}{ Reaction Time [ms] } & Group: $F(2,72)=4.9, p=0.010, \eta^{2}=0.12$ & $p=0.228$ & $p=0.144$ & $p=0.008$ \\
\hline & Distractor category: $F(1,72)=0.49, p=0.484, \eta^{2}=0.01$ & - & - & - \\
\hline & Group $\times$ Distractor category: $F(2,72)=0.038, p=0.963, \eta^{2}=0.001$ & - & - & - \\
\hline & Age: $F(1,72)=9.2, p=0.003, \eta^{2}=0.11$ & - & - & - \\
\hline & Intelligence: $F(1,72)=0.177, p=0.675,{ }^{2}=0.002$ & - & - & - \\
\hline & Hospitalization: $F(1,72)=5.05, p=0.028, \eta^{2}=0.07$ & - & - & - \\
\hline \multirow[t]{5}{*}{ Error rate $[\%]$} & Group: $F(2,71)=0.9, p=0.409, \eta^{2}=0.03$ & n. a. & n. a. & n. a. \\
\hline & Distractor category: $F(1,72)=0.0, p=0.99, \eta^{2}=0.03$ & - & - & - \\
\hline & Group $\times$ Distractor category: $F(2,72)=1.08, p=0.346, \eta^{2}=0.03$ & - & - & - \\
\hline & Age $F(1,71)=4.59, p=0.036, \eta^{2}=0.06$ & - & - & - \\
\hline & Intelligence: $F(1,72)=20.62, p<0.001, \eta^{2}=0.22$ & - & - & - \\
\hline
\end{tabular}


Citation: Jordan K, Fromberger P, von Herder J, Steinkrauss H, Nemetschek R, Witzel J, Müller JL (2016) Can We Measure Sexual Interest in Pedophiles Using a Sexual Distractor Task?. J Foren Psy 1: 109. doi:10.4172/2475-319X.1000109

Page 9 of 14

\begin{tabular}{|c|c|c|c|c|}
\hline & Hospitalization: $F(1,72)=1.22, p=0.274, \eta^{2}=0.02$ & - & - & - \\
\hline \multirow[t]{6}{*}{ Fixation latency [ms] } & Group: $F(2,66)=3.59, p=0.033, \eta^{2}=0.10$ & $p=0.042$ & $\mathrm{p}=0.517$ & $p=1.000$ \\
\hline & Distractor category: $F(1,66)=0.15, p=0.70, \eta^{2}=0.00$ & - & - & - \\
\hline & Group $\times$ Distractor category: $F(2,66)=0.26, p=0.773, \eta^{2}=0.01$ & - & - & - \\
\hline & Age: $F(1,66)=0.00, p=0.955, \eta^{2}=0.00$ & - & - & - \\
\hline & Intelligence: $F(1,66)=0.40, p=0.529, n^{2}=0.01$ & - & - & - \\
\hline & Hospitalization: $F(1,66)=0.51, p=0.478, \eta^{2}=0.01$ & - & - & - \\
\hline \multirow[t]{6}{*}{ Relative fixation time [\%] } & Group: $F(2,72)=4.60, p=0.013, n^{2}=0.11$ & $p=0.014$ & $\mathrm{p}=0.364$ & $p=0.1000$ \\
\hline & Distractor category: $F(1,72)=0.04, p=0.847, \eta^{2}=0.00$ & - & - & - \\
\hline & Group $\times$ Distractor category: $F(2,72)=0.92, p=0.403, n^{2}=0.03$ & - & - & - \\
\hline & Age: $F(1,72)=0.16, p=0.687, \eta^{2}=0.00$ & - & - & - \\
\hline & Intelligence: $F(1,72)=0.00, p=0.973, \eta^{2}=0.00$ & - & - & - \\
\hline & Hospitalization: $F(1,72)=0.15, p=0.70, \eta^{2}=0.00$ & - & - & - \\
\hline
\end{tabular}

Table 3: Statistical results of the GLM for mental rotation performance and eye movements in the sexual distractor task with respect to the subject groups.

\section{Eye movements in the sexual distractor task}

Figure 3 presents the means, standard errors for eye movements in the sexual distractor task with respect to the two different sexual distractors.

\section{Fixation latency- results within groups}

Repeated measure GLMs for each group failed to show any effects with respect to the distractor category: non-forensic controls: $\mathrm{F}$ $(1,45)=0.84, \mathrm{p}=0.366, \mathrm{\eta}^{2}=0.02$, forensic controls: $\mathrm{F}(1,4)=2.24, \mathrm{p}=0.209$, $\eta^{2}=0.36$, pedophiles: $F(1,21)=2.08, p=0.164, \eta^{2}=0.09$ (Figure $3 a$ ).

\section{Fixation latency - results between groups}

As can be seen from Figure 3a, pedophiles exhibited shortest fixation latencies towards sexual distractors compared to both control groups (Table S5 for analysis without covariates). Detailed statistical results of the mixed design GLM with the covariates age, intelligence and hospitalization are presented in Table 3 . The analysis yielded a significant main effect for the group $\left(F(2,66)=3.59, p=0.033, \eta^{2}=0.10\right)$ with significantly shorter fixation latencies for sexual distractors in pedophiles compared to the forensic control group $(p=0.042)$. No further main effects or interactions were found. Interestingly, none of the covariates had a significant influence.

\section{Relative fixation time - results within groups}

The repeated measure GLM for the non-forensic control group revealed a main effect for the distractor category with longer fixation times for adult sexual distractors than for child sexual distractor ( $F$ $(1,49)=11.42, \mathrm{p}=0.001, \eta^{2}=0.19$, post-hoc test: $\left.\mathrm{p}=0.001\right)$. Although, a similar tendency was seen for the forensic control group, this difference did not reach significance $\left(F(1,6)=1.44, p=0.276, \eta^{2}=0.19\right)$.
Pedophiles did not show fixation time differences with respect to distractor category $\left(\mathrm{F}(1,21)=0.38, \mathrm{p}=0.542, \mathrm{\eta}^{2}=0.02\right)$ (Figure $3 \mathrm{~b}$ ).

\section{Relative fixation time - results between groups}

Pedophiles differed from both control groups with clearly longer relative fixation times to sexual distractors (Figure $3 \mathrm{~b}$ and Table S5 for analysis without covariates). Detailed statistical results of the mixed design GLM with covariates age, intelligence and hospitalization are presented in Table 3. The analysis yielded a significant main effect for the group with significantly longer fixation times for sexual distractors in pedophiles compared to forensic controls $(\mathrm{F}(2,72)=4.60, \mathrm{p}=0.013$, $\eta^{2}=0.11$, post-hoc test: $\left.\mathrm{p}=0.014\right)$. No further effects or interactions were found. None of the covariates had a significant influence.

\section{Age preference index and discriminant variability}

In order to further analyze the data regarding the age preference for the sexual distractors, we computed an age preference index (API, data analysis). Furthermore, we combined the groups to compare pedophiles $(n=21)$ with non- pedophiles (both control groups $(n=57)$. Table S3 in the supplementary material presents means, standard deviation and statistical results for the groups. Analysis of the API for RT, error rate and fixation latency did not reveal any significant group differences.

The API for relative fixation time was about zero for pedophiles, indicating almost no differences between fixation times for adult and for child sexual distractors (Table S3). A positive value was found in the non-pedophilic group, indicating longer fixation time to adult sexual stimuli than to child sexual stimuli. Again, the GLM including covariates did not reveal any group differences $(F(1,73)=1.571$, $\left.p=0.214, \eta^{2}=0.021\right)$, even none of the covariates itself had a significant influence. But this variable was of interest because it was the only 
variable which showed a group effect if covariates were excluded from analysis $\left(\mathrm{F}(1,77)=5.630, \mathrm{p}=0.020, \mathrm{\eta}^{2}=0.068\right.$, also Table S6). The ROCanalysis revealed that the API for the relative fixation time discriminated between pedophiles and non-pedophiles with moderate accuracy (AUC=0.697, $\mathrm{p}=0.007$ ). Using a cutoff criterion of $0.217 \%$, the API differed between pedophiles and non-pedophiles with a sensitivity of $71.9 \%$ (probability that a pedophile will be correctly classified as pedophilic). The specificity, i.e., the probability that a nonpedophile will be correctly classified a non-pedophilic was $63.6 \%$ (Table S3).
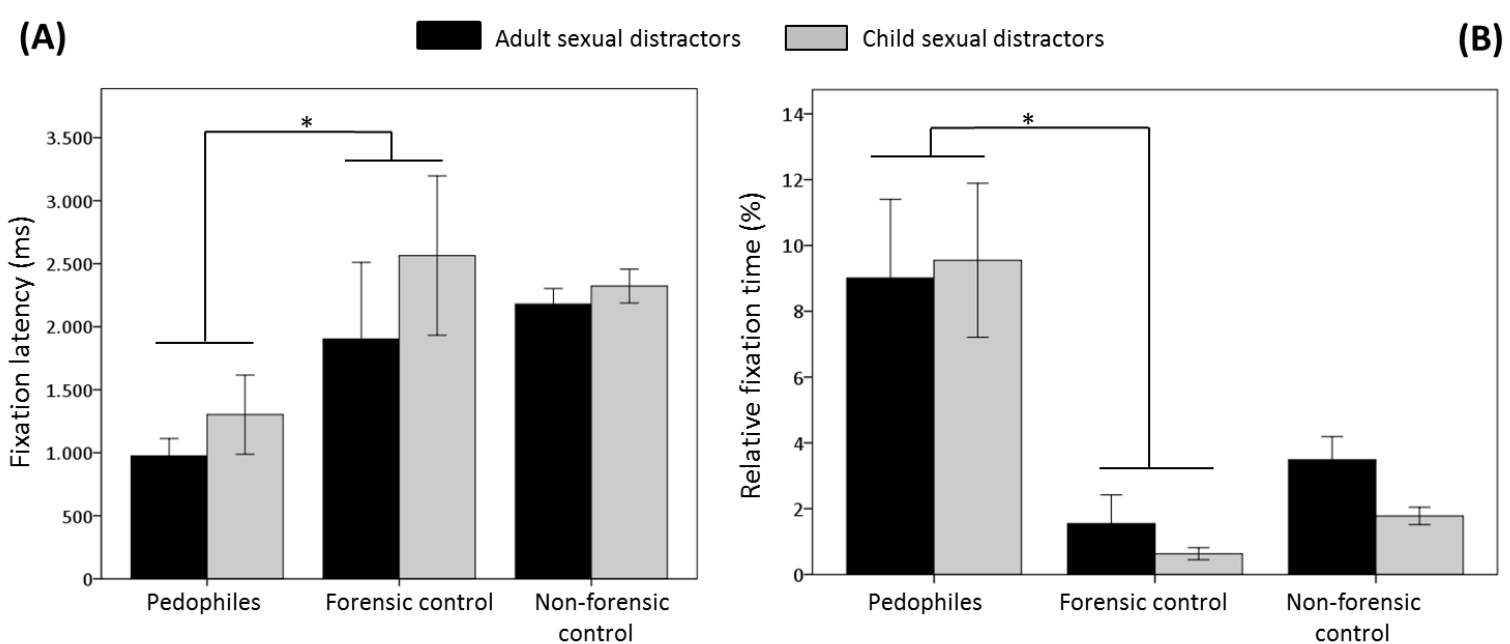

Figure 3: Eye movements in the sexual distractor task with respect to subject group. Means and standard errors are shown of the fixation latency for the first fixation to a sexual distractor (A) and the relative fixation time (B). Black bars: eye movements if the sexual distractor was an adult. Grey bars: eye movements if the sexual distractor was a child. ${ }^{*} \mathrm{p}<0.05$ significant differences between pedophiles and forensic control group independently of distractor category.

\section{Discussion}

The objective of this study was to measure sexual interest under cognitive load in pedophiles, forensic control patients and healthy subjects. We used behavioral as well as continuous eye tracking measures to analyze the responses of the subjects. The reported results demonstrated mixed effects. Our approach worked well in the healthy male subjects, but pedophiles and forensic control patients exhibited different and unexpected behavior.

\section{Measurement of sexual interest under cognitive load - cognitive performance}

In healthy subjects, the expected impairment of cognitive performance was seen if the sexual distractor was an adult. Subjects of the non-forensic control group responded with longer RTs and higher error rates in the mental rotation task if an adult sexual distractor was simultaneously presented compared to a child sexual distractor. Neither pedophiles nor the forensic control group showed a main effect for distractor category for any of the dependent variables. Concerning group differences in mental rotation performance, contrary to our hypotheses, no effect of the distractor category was seen. This striking group differences could mainly be explained by the covariates age of subjects, intelligence or hospitalization.

RTs and error rates in the non-forensic control group was well within the expected range. Stimuli used in the current study were among the set, used by Paschke et al. [41]. In this task, healthy male subjects rotated figures with angular disparity of 80 degrees within $2500 \mathrm{~ms}$, with an error rate of about $10 \%$. The non-forensic control group in the current study achieved only slightly lower results. Hence, it can be concluded, that if subjects perform adequately, i.e., if the difficulty of the test is adjusted to individual ability, then the expected impairment of performance can be seen. These results support the aforementioned the SCID, which occurs when a salient sexual stimulus triggers attentional processes, interfering with or limiting attention to other tasks [14].

Both forensic groups performed much poorer than the non-forensic control group with longer RTs and higher error rates. We suspect that it was due to this poor mental rotation performance of both forensic groups that we did not see any differential effects with respect to sexual distractor category. We cannot exclude that this special mental rotation task was too difficult for the forensic patients, considering the high error rate of about $30 \%$. The strong group effect regarding the error rate could mostly be explained by group differences regarding intelligence, but also with respect to age differences. The mean IQ of both forensic groups was below the normal range (mean IQ=100 \pm 15 ) [50], which was a somewhat unexpected result. Research showed that sexual offenders scored lower in IQ than nonsexual offenders, but the scores were within the normal range (mean score of sex offenders higher than 90) [51,52]. The group effect for the RT could only partly result from age and hospitalization differences between groups, because it remained significant even after controlling for age. The decrease of processing speed with older age has been well documented $[53,54]$. Contrary to Suchy et al. [55], we did not find a generally slower performance in pedophiles compared to the control groups. However, our data with longer RTs in both forensic groups compared to the non-forensic control group seem to reflect the results with other cognitive tasks. In two different Stroop tasks, Ciardha and Gormley [16] also described slower RTs in sex offenders (against at least one child) compared to non-offenders. 
Sex offenders seem to exhibit lower overall cognitive performance in comparison to the general population [56]: Based on a meta-analysis about neuropsychological studies of sex offenders, Joyal et al. [56] found a highly significant overall effect size with all cognitive measures combined. Our results in the MRT, as a measure for the general mental rotation performance, may partially reflect this overall lower cognitive performance in sex offenders. To the best of our knowledge, only one study tested the mental rotation performance in sex offenders [57]. In this study, middle aged sex offenders (rapists and child molesters) achieved an MRT-score of about 6.48 (SD 4.21), which is slightly higher than the score for sex offenders in our study. Ponseti et al. [57] found no differences between the rapists and the child molesters.

Our data contradict the results by Mokros et al. [15], who found that using the CRT task, child molesters and non-sex offenders could be discriminated with high sensitivity and high specificity. However, the CRT seems to be a very easy task in comparison to the mental rotation task used in the current study. In the CRT, the task for the subject is to locate a dot which is superimposed on one of five locations depicted sexual stimuli. General RTs and error rates of the forensic subjects in the CRT were very much lower than RTs and error rates in the mental rotation task. It would be of interest, if an individual adjustment of the difficulty of our task could improve performance make potentially differential effects visible (below).

\section{Measurement of sexual interest under cognitive load - eye movements}

Early attentional processes: In contrast to our hypotheses, the latency of the first fixation toward sexual distractors did not differ between the distractor categories (adult, child). This was the case among all three groups. With respect to differences between groups, pedophiles exhibited significantly shorter fixation latencies to all sexual distractors than the forensic control group; still analysis failed to show any main or interaction effects for the distractor category.

At first glance, these results seem to be in contrast to the study by Fromberger et al. [21]. In an initial orientation paradigm, pedophiles and non-pedophiles could be discriminated with high sensitivity and high specificity based on early attentional processes, i.e., the fixation latency [21]. Early attentional processes are considered to be automatic and probably more difficult to manipulate compared to late controlled attentional processes, which are consciously accessible $[58,59]$. Interestingly, however, in a visual search task, Siebold et al. [60] found that initial saccades elicited after $250 \mathrm{~ms}$ were completely unaffected by salience and were increasingly led in line with task demands with increasing RT. Moreover, second saccades, elicited afterwards, were completely unaffected by salience and were consistently goal-driven [60]. As can be seen from Figure 3, in our study, first fixations to sexual distractors appeared clearly later than $250 \mathrm{~ms}$. Hence, it seems to be possible that fixation latencies after $250 \mathrm{~ms}$ were susceptible to modulation according to task demands or manipulation. In this context it has also to be mentioned that fixation latency in our study represents the latency of the first fixation to a specific AOI, thus do not exclusively represents the absolutely first fixation in a trial, but also later fixations. Hence, we suggest that already early attentional processes could be directed to the mental rotation figures and not to the sexual distractors. Interestingly, applying the initial orientation paradigm (IO), Fromberger et al. [21] demonstrated that also fixation latencies about $1000 \mathrm{~ms}$ could be clearly driven by sexual preference. In contrast to the current study, in the IO paradigm sexual stimuli served as targets, which had to be directly viewed and evaluated.
Recently Breitschuh et al. [61] showed that these fixation latencies were susceptible to manipulation. Nevertheless, subjects could correctly be classified as hetero- and homosexual.

Regarding group differences, pedophiles had shorter fixation latencies toward sexual distractors than the control groups, especially compared to the forensic control group. This might be a hint, that early top-down processes did not play the same role in pedophiles than in the control groups. With respect to these top-down processes, additional analyses comparing eye movements to mental rotation figures and to sexual distractors would be of interest. It might be possible, that impaired inhibitory control functions, which were reported for sex offenders against children, could be possible factors $[56,62]$.

Late attentional processes: Concerning the relative fixation time, healthy subjects viewed adult sexual distractors significantly longer than child sexual distractors. This result supported our hypothesis regarding late attentional processes. Interestingly, additional analysis showed that the longer subjects viewed sexual distractors, the longer the RT in the mental rotation task, if an adult sexual distractor was presented $(\mathrm{r}=0.513, \mathrm{p}<0.001)$. This result supports the theory of the SCID at the eye movement level [63]. The association of RT in our cognitive task and time of watching the sexually relevant distractors, i.e., the relative fixation time, indicates that the emotional state (elicited by viewing sexually relevant stimuli) could be the cause of the attentional bias and the subsequent delayed task processing.

In the forensic control group, the expected main effect for the distractor category was only seen descriptively, with slightly longer fixation times on adult sexual distractors compared to child sexual distractors. For the pedophiles, no effect for the distractor category was seen. Concerning differences between groups, pedophiles exhibited significantly longer relative fixation times for sexual distractors than forensic controls. Interestingly none of the covariates had a significant influence. Thus, those factors could not explain group differences regarding late attentional processes. In this context it is striking, that the two forensic groups demonstrated different behavior. Both performed poorly in the cognitive task, with longer RTs and higher error rates than the non-forensic control group. Concerning eye movements, however pedophiles and forensic controls behaved differently. Forensic controls exhibited an eye movement pattern which was more similar to healthy subjects with late fixation latencies toward sexual distractors and a small proportion of relative fixation time on sexual distractors. Hence, we conclude that besides a poor performance, forensic control patients directed their attention to the mental rotation figures rather than to sexual distractors. Clearly, we cannot exclude that this eye movement behavior was mainly driven by the motivation to avoid viewing the sexual distractors. Still, in contrast pedophiles did not direct their attention to mental rotation stimuli as much as controls; they watched the sexual distractors earlier and longer. As mentioned above, it would be of interest to compare eye movements towards sexual distractors and mental rotation stimuli, in order to gain more insight in the attentional processes and behavior of our groups.

The API for the relative fixation time was significantly different between pedophiles and non-pedophiles. A higher API in nonpedophiles represents longer fixation times for adults than for children. However, the analysis of covariance demonstrated that differences according to the age of the subjects, intelligence and hospitalization could explain this effect, even if none of the covariate itself had a significant influence. The ROC-analysis yielded moderate 
discrimination accuracy between pedophiles and non-pedophiles. These results are in contrast to Fromberger et al. [21] and Mokros et al. [15] who demonstrated high discrimination ability for their experimental designs. As discussed above, though, both designs used a much easier task than the task used in the current study. One disadvantage of these easier tasks could be the probably higher susceptibility to manipulation by the subjects. A more comparable task, the Pictorial-Modified Stroop task could not sufficiently discriminate between sexual offenders against children and nonoffenders [16].

\section{Potential and Limitations}

All in all, our results lead to the conclusion that our experimental approach works well with healthy subjects. Nevertheless, in the current version, it seems to be not applicable to measure sexual interest in forensic patients. Contrary to our hypotheses, especially pedophile, but also forensic control patients exhibited rather different and unexpected behavior. Low sample size, especially in the forensic control group and poor mental rotation performance could have contributed to these results. Further studies should examine if larger sample size and an adjustment of the difficulty of the cognitive test to individual abilities of the subjects could improve performance and could make potentially differential effects visible. It is one advantage of this special task, that the difficulty of the task can be changed gradually by increasing or decreasing the angular disparity between the two rotation figures $[38,41]$.

Additionally, the low category specificity in the pedophilic group for all measured variables, including stimulus rating has to be mentioned. Pedophiles showed higher valence and arousal rating and also larger viewing times (VT) for child stimuli than controls. In the mental rotation task, they exhibited longer relative fixations times to sexual distractors compared to the control groups. But they did not show the expected within-group difference with higher ratings, longer viewing times and longer fixation times for child compared to adult stimuli. One reason could be that pedophiles exhibited a socially desirable response pattern. This assumption is supported by significant higher valence and arousal ratings for adult than for child stimuli in this group. Further studies with pedophilic subjects, who do not show such socially desirable response patterns are necessary.

Another aspect concerns the nature of our task. According to a new approach by Schmidt et al. [64], VT, IAT and the initial orientation paradigm belong to so called task-relevant indirect measures of deviant sexual interest, because participants have to categorize or discriminate task-relevant sexual categories. CRT, Pictorial-Modified Stroop and the mental rotation task used in the current study are task-irrelevant indirect measures of deviant sexual interest. Subjects have to solve cognitive tasks, while being distracted by simultaneously presented task-irrelevant sexual features. Schmidt et al. [64] argued that taskrelevant measures should be superior to task-irrelevant measures, because in task-relevant measures sexual features of stimuli cannot be ignore. In support of this, Rönspies et al. [65] showed the superiority of two task-relevant measures of sexual interest (the VT-task and the Implicit Relational Assessment Procedure, IRAP) compared to the CRT, in predicting sexual orientation in hetero- and homosexual men. Thus, the nature of our task, as a task-irrelevant indirect measure of deviant sexual interest, could have contributed to the low to moderate discrimination accuracy between the groups, because subjects potentially could ignore sexual features. Otherwise we assume that in our task susceptibility to manipulation by participants should be lower than in task-relevant and easier indirect measures. It should be difficult to systematically manipulate responses to task-irrelevant sexually preferred features (e.g., attention allocation, arousal, eye movements) if being engaged in this challenging cognitive task. But this assumption has to be proved. Furthermore, an analysis of the temporal course of the continuously recorded eye movements could potentially give more insight into the discussion about the underlying mechanisms of those tasks, e.g., early attentional capture and/or later disengagement from salient (sexual) stimulus [64]. Moreover, with respect to attentional control processes, additional analyses comparing eye movements to mental rotation figures and to sexual distractors could be of interest, in order to gain more insight in the attentional processes and behavior of our groups.

\section{Conclusions}

In this study we aimed to measure sexual interest under cognitive load in pedophiles, forensic control patients and healthy subjects. The results reported mixed effects. Our approach to measure sexual interest under cognitive load worked well with healthy male subjects. Interestingly, early attentional processes seem to be modulated by task demands rather than by stimulus salience. Further studies should examine if an adjustment of the difficulty of the cognitive test to the individual abilities of the subjects could improve performance and could make potentially differential effects visible.

\section{Acknowledgement}

Special thanks go to Mona Klöckner for careful linguistic reading.

\section{References}

1. American Psychiatric Association (2013) Diagnostic and statistical manual of mental disorders: DSM-5, 5th edn., Washington DC, USA.

2. Hanson RK, Morton-Bourgon KE (2005) The characteristics of persistent sexual offenders: a meta-analysis of recidivism studies. J Consult Clin Psychol 73: 1154-1163.

3. Kalmus E, Beech AR (2005) Forensic assessment of sexual interest: A review. Aggress Violen Behav 10: 193-217.

4. Snowden RJ, Craig RL, Gray NS (2011) Indirect behavioral measures of cognition among sexual offenders. J Sex Res 48: 192-217.

5. Seto MC, Kingston DA, Bourget D (2014) Assessment of the paraphilias. Psychiatr Clin North Am 37: 149-161.

6. Schmidt AF, Gykiere K, Vanhoeck K, Mann RE, Banse R (2014) Direct and Indirect Measures of Sexual Maturity Preferences Differentiate Subtypes of Child Sexual Abusers. Sex Abuse 26: 107-128.

7. de Houwer J, Moors A (2010) Implicit measures: Similarities and differences. In: Gawronski B, Payne BK (eds.) Handbook of implicit social cognition: Measurement, theory, and applications. New York, Guilford Press, USA, pp: 176-193.

8. Banse R, Schmidt AF, Clarbour J (2010) Indirect Measures of Sexual Interest in Child Sex Offenders: A Multimethod Approach. Crim Justice Behav 37: 319-335.

9. Gray NS, Brown AS, MacCulloch MJ, Smith J, Snowden RJ (2005) An implicit test of the associations between children and sex in pedophiles. J Abnorm Psychol 114: 304-308.

10. Everaerd W (1989) Commentary on Sex Research. J Psychol Human Sex 1:3-15.

11. Spiering M, Everaerd W (2007) The sexual Unconscious. In: Janssen E (ed.) The psychophysiology of sex, Bloomington, Indiana University Press, Indiana, USA, pp: 166-183.

12. Fromberger P, Jordan K, Steinkrauss H, Jakob HV, Georg S, et al. (2013) Eye movements in pedophiles: Automatic and controlled attentional 
processes while viewing prepubescent stimuli. J Abnorm Psychol 122 587-599.

13. Kahneman D (1973) Attention and effort. Prentice Hall series in experimental psychology, Prentice Hall, New Jersey, Englewood Cliffs, USA.

14. Geer JH, Bellard HS (1996) Sexual content induced delays in unprimed lexical decisions: gender and context effects. Arch Sex Behav 25: 379-395.

15. Mokros A, Dombert B, Osterheider M, Zappalà A, Santtila P (2010) Assessment of pedophilic sexual interest with an attentional choice reaction time task. Arch Sex Behav 39: 1081-1090.

16. Ciardha CO, Gormley M (2012) Using a Pictorial-Modified Stroop Task to Explore the Sexual Interests of Offenders Against Sexual Children. Sex Abuse 24: 175-197.

17. Imhoff R, Schmidt AF, Nordsiek U, Luzar C, Young AW, et al. (2010) Viewing time effects revisited: prolonged response latencies for sexually attractive targets under restricted task conditions. Arch Sex Behav 39: 1275-1288.

18. Abel GG, Jordan A, Hand CG, Holland LA, Phipps A (2001) Classification models of child molesters utilizing the Abel Assessment for sexual interest. Child Abuse Negl 25: 703-718.

19. Babchishin KM, Nunes KL, Kessous N (2014) A multimodal examination of sexual interest in children: a comparison of sex offenders and nonsex offenders. Sex Abuse 26: 343-374.

20. Imhoff R, Schmidt AF, Weiß S, Young AW, Banse R (2012) Vicarious Viewing Time: Prolonged Response Latencies for Sexually Attractive Targets as a Function of Task- or Stimulus-Specific Processing. Arch Sex Behav 41: 1389-1401.

21. Fromberger P, Jordan K, Steinkrauss H, von Herder J, Witzel J, et al. (2012) Diagnostic accuracy of eye movements in assessing pedophilia. J Sex Med 9: 1868-1882.

22. Compton RJ (2003) The interface between emotion and attention: a review of evidence from psychology and neuroscience. Behav Cogn Neurosci Rev 2: 115-129.

23. Ohman A (2009) Of snakes and faces: an evolutionary perspective on the psychology of fear. Scand J Psychol 50: 543-552.

24. Öhman A, Flykt A, Esteves F (2001) Emotion drives attention: Detecting the snake in the grass. J Exp Psychol-Gen 130: 466-478.

25. Krupp DB (2008) Through evolution's eyes: extracting mate preferences by linking visual attention to adaptive design. Arch Sex Behav 37: 57-63.

26. Fromberger $\mathrm{P}$, Jordan $\mathrm{K}$, von HJ, Steinkrauss $\mathrm{H}$, Nemetschek R, et al. (2012) Initial Orienting Towards Sexually Relevant Stimuli: Preliminary Evidence from Eye Movement Measures. Arch Sex Behav 41: 919-928.

27. Nummenmaa L, Hietanen JK, Santtila P, Hyönä J (2012) Gender and visibility of sexual cues influence eye movements while viewing faces and bodies. Arch Sex Behav 41: 1439-1451.

28. Hall CL, Hogue T, Guo K (2014) Sexual cognition guides viewing strategies to human figures. J Sex Res 51: 184-196.

29. Bolmont M, Cacioppo JT, Cacioppo S (2014) Love is in the gaze: an eyetracking study of love and sexual desire. Psychol Sci 25: 1748-1756.

30. Tan L, Grace RC (2008) Social desirability and sexual offenders: a review. Sex Abuse 20: 61-87.

31. von Herder J, Jordan K, Fromberger P (2014) The detection sexual interest under cognitive load. In: Rösler M, Müller JL, Briken P, et al (eds.) EFPPP Jahrbuch 2014: Empirical research in forensic psychiatry, psychology and psychotherapy, support. MWV Medizinisch Wissenschaftliche Verlagsgesellschaft, Berlin, Germany, pp: 27-41.

32. Kinsey AC, Pomeroy WB, Martin CE (1948) Sexual behavior in the human male. Philadelphia, Saunders Co., USA.

33. Seto MC, Lalumiere ML (2001) A Brief Screening Scale to Identify Pedophilic Interests Among Child Molesters. Sex Abuse 13: 15-25.

34. Seto MC, Harris GT, Rice ME, Barbaree H (2004) The Screening Scale for Pedophilic Interests Predicts Recidivism Among Adult Sex Offenders with Child Victims. Arch Sex Behav 33: 455-466.

35. Shepard RN, Metzler J (1971) Mental rotation of three-dimensional objects. Science 171: 701-703.
36. Peters M, Battista C (2008) Applications of mental rotation figures of the Shepard and Metzler type and description of a mental rotation stimulus library. Brain and cognition 66: 260-264.

37. Zacks JM (2008) Neuroimaging studies of mental rotation: a metaanalysis and review. J Cogn Neurosci 20: 1-19.

38. Lohman DF (1986) The effect of speed-accuracy tradeoff on sex differences in mental rotation. Percept Psychophys 39: 427-436.

39. Vandenberg SG, Kuse AR (1978) Mental Rotations: A Group Test of Three-Dimensional Spatial Visualization. Percept Mot Skills 47: 599-604.

40. Peters M, Laeng B, Latham K, Jackson M, Zaiyouna R, et al. (1995) A redrawn Vandenberg and Kuse mental rotations test: different versions and factors that affect performance. Brain Cogn 28: 39-58.

41. Paschke K, Jordan K, Wüstenberg T, Baudewig J, Leo Müller J (2012) Mirrored or identical--is the role of visual perception underestimated in the mental rotation process of 3D-objects?: a combined fMRI-eye tracking-study. Neuropsychologia 50: 1844-1851

42. Pacific Psychological Assessment Corporation (2004) The NRP (Not Real People) stimulus set for the assessment of sexual interest, Victoria, BC, Canada.

43. Laws DR, Gress CL (2004) Seeing things differently: The viewing time alternative to penile plethysmography. Legal Criminol Psychol 9: 183-196.

44. Tanner JM, Weber KH (1962) Growth and Maturation of the Human. G. Thieme, Stuttgart, USA.

45. Henderson JM (2003) Human gaze control during real-world scene perception. Trends Cogn Sci 7: 498-504.

46. Buodo G, Sarlo M, Palomba D (2002) Attentional resources measured by reaction times highlight differences within pleasant and unpleasant, high arousing stimuli. Motiv Emotion 26: 123-138.

47. Salvucci DD, Goldberg JH (2000) Identifying fixations and saccades in eye-tracking protocols. In: Duchowski AT (eds) the symposium, New York, ACM Press, USA, pp: 71-78.

48. Armstrong T, Olatunji $\mathrm{BO}$ (2012) Eye tracking of attention in the affective disorders: a meta-analytic review and synthesis. Clin Psychol Rev 32: 704-723.

49. Youden WJ (1950) Index for rating diagnostic tests. Cancer 3: 32-35.

50. Wechsler D (2006) Wechsler Intelligence Scale for Adults: AS; Translation and adaptation of the WAIS - III of Davis changer. Frankfurt, Harcourt Test Services, Germany.

51. Blanchard R, Kolla NJ, Cantor JM, Klassen PE, Dickey R, et al. (2007) IQ, handedness, and pedophilia in adult male patients stratified by referral source. Sex Abuse 19: 285-309.

52. Cantor JM, Blanchard R, Robichaud LK, Christensen BK (2005) Quantitative reanalysis of aggregate data on IQ in sexual offenders. Psychol Bull 131: 555-568.

53. Salthouse TA (1996) The processing-speed theory of adult age differences in cognition. Psychol Rev 103: 403-428.

54. Simpson T, Camfield D, Pipingas A, Macpherson H, Stough C (2012) Improved Processing Speed: Online Computer-based Cognitive Training in Older Adults. Educ Gerontol 38: 445-458.

55. Suchy Y, Eastvold AD, Strassberg DS, Franchow E (2014) Understanding processing speed weaknesses among pedophilic child molesters: Response style vs. Neuropathology. J Abnorm Psychol 123: 273-285.

56. Joyal CC, Beaulieu-Plante J, de Chantérac A (2014) The neuropsychology of sex offenders: a meta-analysis. Sex Abuse 26: 149-177.

57. Ponseti J, Vaih-Koch SR, Bosinski HAG (2001) Etiology of sexual offenders : Neuropsychological parameters and comorbidity. Sexuologie 8: 65-77.

58. Nummenmaa L, Hyona J, Calvo MG (2006) Eye movement assessment of selective attentional capture by emotional pictures. Emotion 6: 257-268.

59. Calvo MG, Lang PJ (2004) Gaze Patterns When Looking at Emotional Pictures: Motivationally Biased Attention. Motiv Emotion 28: 221-243.

60. Siebold A, van Zoest W, Donk M (2011) Oculomotor evidence for topdown control following the initial saccade. PLoS One 6: e23552. 
Citation: Jordan K, Fromberger P, von Herder J, Steinkrauss H, Nemetschek R, Witzel J, Müller JL (2016) Can We Measure Sexual Interest in Pedophiles Using a Sexual Distractor Task?. J Foren Psy 1: 109. doi:10.4172/2475-319X.1000109

Page 14 of 14

61. Breitschuh S, Fromberger P, Jordan K (2016) Use of eye tracking method for detecting sexual preferences : a investigation of faking eye movements. In: Müller JL, Briken P, Rösler M (eds.) EFPPP Jahrbuch 2016: Empirical research in forensic psychiatry, psychology and psychotherapy, support MWV Medizinisch Wissenschaftliche Verlagsgesellschaft, Berlin, Germany.

62. Suchy Y, Whittaker JW, Strassberg DS, Eastvold A (2009) Neurocognitive differences between pedophilic and nonpedophilic child molesters. J Int Neuropsychol Soc 15: 248-257.

63. Gress CL, Anderson JO, Laws DR (2013) Delays in attentional processing when viewing sexual imagery: The development and comparison of two measures. Legal Criminol Psych 18: 66-82.
64. Schmidt AF, Banse R, Imhoff R (2015) Indirect measures in forensic Contexts. In: Ortner TM, van de Vijver FJR (eds.). Behavior-based assessment in psychology: Going beyond self-report in the personality, affective, motivation, and social domains Boston, Hogrefe, Maryland, USA, pp: 173-194.

65. Rönspies J, Schmidt AF, Melnikova A, Krumova R, Zolfagari A, et al. (2015) Indirect Measurement of Sexual Orientation: Comparison of the Implicit Relational Assessment Procedure, Viewing Time, and Choice Reaction Time Tasks. Arch Sex Behav 44: 1483-1492. 